\title{
The Politics of 'Usable' Knowledge: Examining the Development of Climate Services in Tanzania
}

\author{
Meaghan Daly ${ }^{*} \&$ Lisa Dilling ${ }^{2,3}$ \\ ${ }^{1}$ Department of Environmental Studies \\ University of New England \\ Biddeford, ME, 04005, USA \\ ORCID ID: 0000-0002-6069-8290 \\ ${ }^{2}$ Environmental Studies Program \\ University of Colorado Boulder \\ Boulder, CO, 80309, USA \\ ORCID ID: 0000-0001-5061-0809 \\ ${ }^{3}$ Center for Science and Technology Policy Research \\ Cooperative Institute for Research in Environmental Sciences \\ University of Colorado Boulder \\ Boulder, CO 80309, USA \\ * Contact details for corresponding author: \\ Email: mdaly8@une.edu \\ Tel: +1 207-468-2715
}

Acknowledgements: The authors gratefully acknowledge the support of the National Science Foundation SES - Division of Science, Technology, and Society (Grant No. 1354542), the U.S. Agency for International Development (USAID) Climate Change Resilient Development Small Grants Program (Grant No. CCRDACD0001), and the University of Colorado Boulder Innovative Seed Grant Program. The authors thank Dr. Mara Goldman, Dr. Eric Lovell, Dr. Elifuraha Laltaika, Mr. Alais Morindat, and Mr. Shayo Alakara for their support of the project. The authors are also grateful to residents in the villages of Arkaria and Kiserian, the Tanzanian Meteorological Agency, and the many other individuals and organizations in Tanzania who participated in this research.

Compliance with Ethical Standards: Data collection undertaken with human subjects was reviewed and approved the University of Colorado Boulder Internal Review Board (IRB) under Protocol \#14-0017 and the Tanzania Commission for Science and Technology under research permits No. 2013-105-NA-2013-7, No. 2014-63-ER-2013-17, and No. 2015-94-ER-2013-17. 


\begin{abstract}
The field of climate services has arisen rapidly out of a desire to enable climate science to meet the information needs of society to respond to climate variability and change. In order for knowledge to be 'usable' for decision-making, in the field of climate adaptation and beyond, it must meet the criteria of credibility, salience, and legitimacy (Cash et al. 2003). Deliberate 'co-production' of knowledge between 'producers' and 'users' has the potential to increase usability for decision-making and policy in some contexts. While co-production is increasingly advanced as an instrumental approach to facilitate the production of 'usable' climate services, such efforts have paid scant attention to the role of power relations. In this article, we bring together literature on normative approaches to co-production — which treats co-production as an instrumental means to an end - with analytical interpretations of coproduction within the field of Science and Technology Studies to examine efforts to develop 'usable' climate services in Tanzania. We show that without reflexive processes that are explicitly attentive to power dynamics, normative co-production within climate services development can serve to reinforce, rather than overcome, power imbalances among actors.
\end{abstract}

Key Words: usable knowledge, climate services, co-production, boundary work, Tanzania 


\section{Introduction}

The field of climate services has grown out of a desire to more effectively enable climate science to meet the information needs of society to respond to climate variability and change (Vaughan \& Dessai 2014; Visbeck 2008). While there are multiple definitions of climate services (Brasseur \& Gallardo 2016), all highlight the overarching goal of producing climate-related data, information, products, or knowledge that are 'usable' for decision-making, planning, or policy.

Climate services were elevated as a major international agenda following the launch of the Global Framework for Climate Services (GFCS) in 2009 (Hewitt, Mason, \& Walland 2012). In the decade since, significant, and growing, amounts of funding have been allocated to support the development of climate services. For example, in 2014/15, over \$25 billion USD was invested in climate services globally (Georgeson, Maslin, \& Poessinouw 2017). There has been emphasis on building capacities in the Global South, where climate services are a key component of enabling climate adaptation and sustainable economic development (WMO 2011). Given the rapidly expanding investment at the global scale, there is a pressing need for research to understand how the broader project of producing 'usable' climate services is translated in specific places.

In order for scientific climate knowledge to be 'usable,' there is frequently a need for iterative interaction between 'users' and 'producers' as part of a process of 'co-production,' whereby science and policy mutually shape and reinforce each other (Dilling \& Lemos 2011; Lemos \& Morehouse 2005). Coproduction has caught on rapidly within the broader realm of climate research (Bremer \& Meisch 2017), and in the field of climate services more specifically (e.g., Kruk et al. 2017; McNie 2008). While coproduction is increasingly advanced as an instrumental approach to facilitate the production of 'usable' climate services, such efforts have paid scant attention to the role of power relations.

In this paper, we examine power relations within efforts to deliberately co-produce 'usable' knowledge in two climate services projects in Tanzania. There are multiple theoretical foundations and interpretations of co-production, which span the fields of STS, public services administration, development studies, and sustainability science (Miller \& Wyborn 2018; Goldman, Turner, \& Daly 2018; Vincent, Daly, Scannel, \& 
Leathes 2018). In our theoretical framework we bring together literature on normative approaches to coproduction in the field of climate services (e.g. Dilling \& Lemos 2011) — which treat co-production as an instrumental means to an end - with analytical interpretations of co-production within the field of science and technology studies (STS) (e.g. Jasanoff 2004) that stress the fundamental linkages between knowledge and power (Bremer \& Meisch 2017; Lövbrand 2012; Wyborn 2015). In other words, we use analytical coproduction as a lens to examine normative co-productions of climate services, as proposed by Bremer et al. (2019). In doing so, we illustrate how knowledge politics were sidelined within efforts to normatively coproduce 'usable' climate services in Tanzania.

Tanzania is selected as a case study because it has been earmarked for comprehensive investment by international organizations and donors to 'fast-track' climate services development at national and subnational scales (GFCS 2013). Within this context, we examine two separate, but overlapping, climate services projects in Tanzania. These projects illustrate the complex engagements between 'global', 'national', and 'local' actors, all of whom possess different knowledges, world views, goals, and motivations within climate services development. Further, these interactions are superimposed upon the intertwined histories of colonization, failed technocratic development interventions, and applications of Western scientific knowledge in Tanzania (Scott 1998), all of which fundamentally shape extant power relations.

In the remainder of Section 1, we elaborate on our theoretical framing and review the literature to further describe how power is exerted in the production of knowledge, and why we should not expect normative co-production processes to be exempt from its effects. In Sections 2 and 3, we further describe the setting for the case study, as well as the methods for data collection. In Section 4, we present the results. Here, we show that attributes of 'usable' knowledge are relational, rather than fixed, and describe how power relations are both challenged and reinforced through debates about what constitutes 'usable' climate knowledge in the normative co-production of climate services. In particular, we show how different facets of 'usability' - i.e. credibility, salience, and legitimacy (Cash et al. 2003) — are strategically employed by various actors as a means of shoring up the authority of competing knowledge claims in different 
settings, thereby enacting a form of practical politics. In Sections 5 and 6, we discuss the implications of these findings for future research and efforts to co-produce climate services.

\subsection{Co-production, 'Usable' Knowledge, and Climate Services}

Normative, or deliberate, approaches to co-production are increasingly employed within attempts to produce 'usable' knowledge. The recent 'co-production turn' reflects broader calls for science to become more responsive to societal needs (e.g. McNie 2007), as well as accountable to various publics and inclusive of other ways of knowing and being in the world (e.g. Leach, Scoones, \& Wynne 2005). In practice, normative co-production of climate knowledge is described as "a process of producing usable, or actionable, science through collaboration between scientists and those who use science to make policy and management decisions" (Meadow et al. 2015). Such deliberate co-production, through long-term, iterative interaction between producers and users, can enhance usability of climate knowledge for decision-making in some contexts (Cash 2006; Dilling \& Lemos 2011; Prokopy et al. 2017). In their typology of coproduction 'lenses,' Bremer and Meisch (2016) characterized efforts to produce 'usable' knowledge as a normative endeavor. For this reason, we will refer to deliberate efforts to co-produce 'usable' knowledge as normative co-production in the remainder of this paper.

In contrast, analytical conceptualizations of co-production, drawing on the field of STS, examine how knowledge is intrinsically linked to social orders (Jasanoff 2004). The lens of analytical co-production can help to expose and address the power inequities among participants that can constrain normative coproductions of 'usable' knowledge (Fisher et al. 2018; Goldman et al. 2018). Power is exerted in scientific processes through "boundary work" that demarcates science from non-science and enforces constructed hierarchies of knowledge (Gieryn 1999). STS scholars have long recognized that the boundaries between science and other knowledges are maintained through socially embedded practices (Woolgar \& Latour 1986). Within contentious multi-stakeholder participatory arrangements, where boundaries between science and policy become blurred, scientists strategically shore up their authority in the face of new challenges, thereby producing (and reproducing) the legitimacy of knowledge (Esguerra, Beck, \& Lidskog 2017). 
This “tricky business" of boundary work notwithstanding (Hoppe, Wesselink, \& Cairns 2013, p. 283), normative co-production challenges conventional modes of science production and seeks to explicitly open up space to a greater diversity of actors and knowledges. In contrast to 'Mode-1' (Gibbons et al. 1994) or 'loading-dock' approaches (Cash, Borck, \& Part 2006) to science production, in which scientists are the sole arbiters of knowledge, normative co-production seeks to enable inclusive and deliberative knowledgemaking practices (Armitage et al. 2009). This asks all stakeholders to embrace new roles to rework how science is 'done.' In doing so, co-production challenges attendant social orders and embedded power structures. Transforming knowledge production practices can, thus, create opportunities to reconcile imbalances in power; however, if undertaken uncritically co-production can further entrench linear modes of science production (Turnhout et al. 2013).

Debates about the usability of knowledge thus represent struggles at the boundary of science and policy over who possesses the expertise and authority to speak about particular issues. In theory, almost anyone - from national policy-makers, to average citizens — can be a potential user of climate services. Decisions about who is included in participatory processes are, therefore, fundamentally political determinations about whose knowledge 'counts' (Chilvers \& Kearnes 2015). In this way, all "knowledge production practices are strategic sites of power" (Goldman 2006, p. 179), where the scope and nature of issues are framed, defined, and bounded, along with the range of possible responses. However, there have been few studies that explicitly examine the role of power relations in the normative co-production of climate services.

Recognizing the challenges of producing 'usable' knowledge across actors, scales, and epistemologies, Cash et al. (2003) proposed the knowledge system criteria (KSC) framework to examine when and how knowledge can become 'usable' for decision-making. The KSC framework asserts that for knowledge to be 'usable,' it must be considered sufficiently credible (i.e., valid, trust-worthy, sufficient evidence), salient (i.e., relevant, important relative to other sources of knowledge), and legitimate (i.e., inclusive and fair processes, transparent and unbiased, respectful of divergent values and beliefs) amongst various stakeholders and across multiple institutional scales. However, rather than being inherent attributes of 
knowledge, credibility, salience, and legitimacy are continually negotiated through power-laden struggles to define boundaries between science and politics. In this sense, disputes about credibility, salience, and legitimacy are a means of (re-)ordering the boundaries between science and politics. This poses important questions about how debates about the usability of knowledge unfold within normative co-production processes, including whose priorities and perspectives are recognized when assessing credibility, salience, and legitimacy.

Normative co-production remains rife with challenges, because it involves interactions among actors spanning ontological, epistemological, disciplinary, and institutional divides (Berkes et al. 2006). It is also time-consuming and resource-intensive, posing particular challenges in the Global South (Fisher et al. 2018). In these fluid interfaces between multiple actors and knowledges operating within and across institutional scales, there is not always agreement about what is considered 'usable.' Perceptions of usability can shift over time or in relation to different institutional or collaborative arrangements (Leith \& Vanclay 2015; Schut et al. 2013). Thus, while 'usable' knowledge is often treated in apolitical terms (Lövbrand 2011), the normative co-production of any knowledge - including 'usable' climate services - is not in fact neutral contribution to policy- and decision-making. Normative co-production is fundamentally shaped by contested processes, existing power structures, and the social, historical, institutional, and cultural contexts.

In light of these complexities, there is a need for critical and reflexive examinations of normative co-production approaches that aim to produce 'usable' climate services to avoid reinforcing existing inequalities or, worse, exacerbating them. The analytical, STS-based theory of co-production examines the discourses, institutions, identities, and practices through which scientific knowledge gains and maintains power and social authority (Jasanoff 2004). Power is not only exercised through coercive mechanisms (e.g., control of resources, state authority), but also through the "often invisible role of knowledges, expertise, [and] technical practices" that are involved in "shaping, sustaining, subverting or transforming relations of authority" (Jasanoff 2004, p. 4). In particular, we examine how power comes to be lodged within particular social and institutional configurations as part of boundary work that demarcates between science and politics, as well as overt epistemic concerns about how different knowledges interact in practice. 
In this paper, we illustrate the ways in which actors selectively prioritize some knowledge criteria to conform with the instrumental ideals of normative co-production and exert power by (re-)affirming boundaries between knowledges in ways that can help to solidify the authority of scientific knowledge within climate services development. This paper combines the normative KSC framework with the analytical co-production lens from the field of STS to expose how power is exercised within debates about 'usable' knowledge and how this ultimately influenced the co-production of climate services in Tanzania.

\section{Case Study: Co-production of Climate Services in Tanzania}

Tanzania has been the focus of two internationally sponsored initiatives aiming to facilitate coproduction of climate services for adaptation: 1) the Devolved District Climate Financing Project (DCF project), and 2) the Global Framework for Climate Services Adaptation Program in Africa (GFCS project). Both projects sought to enhance adaptive capacity at local scales through the provision of climate services, but each embraced different problem framings; involved divergent sets of actors, institutions, and governance structures; and had contrasting conceptualizations of co-production.

\section{The DCF Project: Actors, Institutions, \& Governance}

As climate finance is increasingly mobilized to support adaptation in developing countries, there is recognition that these initiatives must build upon capacities and reflect priorities at the local level, where the bulk of adaptation actions are implemented (Sharma et al. 2014). In response, the International Institute for Environment and Development (IIED) has piloted numerous devolved climate finance (DCF) initiatives (IIED 2016). The DCF approach emphasizes the importance of knowledge and institutional capacities, along with localized financial support, in enhancing resilience in the face of climate change.

In Tanzania, the two-year DCF project was funded by the U.K. Department for International Development (DfID) and launched in June 2013 in three pilot districts (Longido, Monduli, and Ngorongoro). These districts were selected specifically because they were located in the semi-arid northern part of the country inhabited predominantly by the Maasai ethnic group, where there is high reliance on pastoralism and agro-pastoralism. Implementation of the project was facilitated by the IIED country 
coordinator and district government offices in partnership with two grassroots civil society organizations — Tanzania Natural Resource Forum (TNRF) and HakiKazi Catalyst — but funding was channeled through the Vice President's Office of Regional and Local Governments. In each district, one individual was selected as the Climate Change Focal Point (See Figure 1).

The Tanzania Meteorological Agency (TMA) was a key partner tasked with providing trainings, developing new climate information products, and enhancing flows of climate information to local levels. In this role, TMA was responsible for facilitating: the interpretation and use of scientific climate information; exploration of effective means of disseminating climate information; downscaling of climate information products; and creation of mechanisms for improved dialogue and feedback with local users as part of the development of climate services (IIED 2013).

\section{The GFCS Project: Actors, Institutions, and Governance}

Following the establishment of the Global Framework for Climate Services in 2012, the Norwegian Ministry of Foreign Affairs (MFA) committed \$10 million USD over three years (2014-2016) to support climate services development for the disaster management, food security, and health sectors in Tanzania and Malawi. The project was billed as a 'flagship' to illustrate 'proof of concept,' whereby "major international players" would "work together in a coordinated and holistic way" to "increase the resilience of people most vulnerable to the impacts of weather and climate-related events" (GFCS 2013).

The GFCS project selected two pilot districts (Longido and Kiteto) for implementation in Tanzania. Similar to the DCF project, both pilot districts were located in semi-arid regions with large agro-pastoralist populations. The GFCS project created a two-tiered governance structure, with a Partner Steering Committee at the international level and a Project Development Team at the national level. This two-tiered governance structure was designed to enhance coordination across the numerous international- and national-level project partners (See Figure 1). WMO and TMA played leading roles within these governance structures at the international and national scales respectively, while district governments were only peripherally involved and there was little budgetary allocation or decision-making authority at sub-national 
scales. Thus, in contrast to the DCF project, the GFCS project situated climate science organizations as the leading entities within project governance.

\section{[FIGURE 1 HERE]}

\subsection{The Politics of Labeling Knowledge}

Both the DCF and GFCS projects had a mandate to co-produce usable climate knowledge; however, they employed different conceptualizations of co-production, including what 'counted' as valid knowledge and who was authorized to participate in knowledge-making practices. Yet, at a basic level, both emphasized the importance of collaborating with climate services 'users' and sought to include or combine 'indigenous' knowledge (IK) with Western 'scientific' knowledge (SK). IK and SK were consistently treated as separate domains to be bridged or integrated, which has elsewhere been referred to as the "integration imperative" (Goldman et al. 2018). For example, the DCF project explicitly aimed to enhance the "link between IK and modern weather forecasts and related indicators" (IIED 2013, p. 3).

However, the use of categories such as 'scientific' and 'indigenous' themselves cannot be separated from how these shape and perpetuate power dynamics among co-production participants. Many Maasai referred to their own knowledge as 'traditional' or 'indigenous' (Swahili: maarifa ya kienyeji / asili). Referring to their own knowledge as 'indigenous' can itself be considered a strategic and performative political act on the part of Maasai participants. The government of Tanzania does not recognize any ethnic groups as indigenous - even if they self-identify as such — due to the political implications that may be attached, e.g. ancestral resource access, rights, and land ownership (Hodgson 2011). Thus, the 'indigenous' label is simultaneously a means of solidifying Maasai claims to indigeneity (and associated political power), as well as enhancing standing as legitimate holders of knowledge. On the other hand, many project participants, from the village to the national to the international scale, used the designation of being "more scientific" as shorthand for 'superior' or 'modern' ways of knowing about climate.

As we will elaborate in the results, applying labels such as 'indigenous' and 'scientific' is itself a form of boundary work, inseparable from struggles over the authority and legitimacy of knowledge within normative co-production. In the remainder of the paper, we use the terms 'indigenous' and 'scientific' 
without quotation marks to enhance readability (see also Agrawal 1995) and to accurately portray the descriptions of knowledge employed by research participants themselves within debates over the validity of knowledge within normative co-production processes. However, we do so recognizing that such labels are not value-free and do important work, both discursively and materially.

\section{Methods}

We employed a case study design with multiple embedded units of analysis at both national and village scales in Tanzania. Three methods were used symmetrically at both scales: planned discussion groups (PDGs), semi-structured interviews, and ethnographic observation (O'Reilly 2005; Rubin \& Rubin 2005). A summary of the data collection is provided in Table 1. Data was collected during a total of 20 months of field work carried out by the lead author in Tanzania between June 2013 - August 2016. Village scale data collection was carried out in the villages of Arkaria and Kiserian (in Monduli and Longido Districts respectively). National and international scale data was collected primarily in offices of government agencies, NGOs, and civil society organizations in the cities of Dar es Salaam and Arusha, Tanzania.

\section{[TABLE 1 HERE]}

Interviews were conducted until 'saturation' was reached (see Lofland 2006). Non-structured observation was undertaken at village scale for a cumulative duration of 6 months and at the national scale for a cumulative duration of 3 weeks. This included the observation of the production of the down-scaled seasonal forecast for the pilot districts in the GFCS project. Structured observation entailed participation in 32 events, such as project meetings, conferences, trainings, and workshops, which brought together various stakeholders to facilitate normative co-production of climate services.

At the village scale, interviewees were selected for representation across all sub-villages in each village and stratified according to socio-economic status, gender, and age. At the national scale, interviewees were selected to ensure inclusion of individuals from national and local government departments and agencies, civil society organizations, national NGOs, and international NGOs. PDGs and interviews were conducted by the lead author, who speaks English and Swahili, with the assistance of two Tanzanian research assistants 
(one male, one female) who were fluent in English, Swahili, and Maa. PDGs and interviews were audio recorded and then transcribed and translated into English. Ethnographic notes were written up by hand and then digitized.

All sources of data were analyzed by the first author through an iterative process. Transcripts and ethnographic notes were first analyzed through a process of thematic memoing to inductively identify emergent themes relating to knowledge production, circulation, and application. Ethnographic notes were coded inductively, while transcripts were coded inductively and deductively using NVivo qualitative analysis software (see Bazeley \& Jackson 2013). Inductive coding was used to identify topics of debate or contentious interactions with relation to the usability of knowledge - i.e. boundary work. For example, this included identifying any instance where knowledge claims were questioned or challenged, or else where one epistemic approach was advanced over others. Deductive coding was used to identify discussion of the credibility, salience, and legitimacy — i.e. usability — of knowledge. For example, coding for credibility included any explicit mention of the adequacy, reliability, or trust-worthiness of knowledge (or lack thereof), as well as the processes through which the validity and authority of knowledge is assessed or verified. This iterative analysis aided in the identification of the multiple facets and intersections of power relations, boundary work, and perceptions of 'usability' within co-production of climate services in Tanzania.

\section{Results}

\subsection{Actors and Interactional Boundary Spaces in Normative Co-production of Climate Services}

Approaches to normative co-production differed across the two projects. The DCF project started with the explicit intention of building on IK and included a focus on decision-making contexts and livelihood practices associated with this knowledge (IIED 2011). The GFCS project, on the other hand, employed a top-down approach with no clear intention to incorporate IK; rather, the issue was framed from the start by international project partners in terms of "coproduction of products and processes by climate service providers and end-users... with a focus on the local level" (GFCS 2013, p. 3). Despite these differences in 
approach, the normative impetus to co-produce climate knowledge was externally driven by the international organizations (e.g. IIED, WMO) rather than by the 'local' partners (e.g. TMA, district residents).

How normative co-production was framed and approached had significant implications for who was involved in setting the scope and goals of the projects, including what kinds of knowledge were prioritized. In the DCF project, IIED began by conducting extensive case studies to understand local livelihood dynamics, which resulted in the use of multiple approaches to determining the kinds and sources of knowledge to be included - e.g., participatory resource mapping exercises, consultations with customary leaders (Swahili: viongozi wa mila, Maa: ilaiguanani). IIED also facilitated a multi-day workshop in 2014 to bring together TMA experts and customary leaders to 'share' knowledge. Workshops were followed by the establishment of 'traditional' forecasting groups in each of the target districts.

In contrast, the GFCS project framed normative co-production in terms of facilitating the "enabling environment for the end-users and climate service providers [to] interface at all levels" with a "focus on the local level," but relied primarily on high level consultations (GFCS 2013, p. 3). For example, the project was kicked off with a National Stakeholders' Consultative Workshop held in Dar es Salaam in May 2014 to identify climate information "needs and gaps" among (primarily) national-scale stakeholders within governmental ministries, as well as national and international NGOs (as discussed further in Section 4.2.3). Indeed, there were only six representatives from local government and civil society organizations in the target districts of Kiteto and Longido, out of a total of 67 participants.

Despite the different starting points, TMA's involvement as the authoritative knowledge provider and facilitator of normative co-production was similar across the two projects. TMA's central role as the primary holder of knowledge in both projects can be attributed to two factors: 1) existing norms and institutional structures in Tanzania and 2) an overarching problem framing across both projects that IK was insufficient and needed to be bolstered (or supplanted) by SK to enable adaptation to climate change. Under legal mandates in Tanzania, TMA is the only entity officially authorized to distribute climate information through the bureaucratic structures designated in national policies (Daly, West, \& Yanda 2016). Despite broader 
national attempts toward decentralization in Tanzania since the 1970s and a renewed push for devolution of decision-making powers since the mid-1990s (Mollel \& Tollenaar 2013), the production and circulation of climate information and services under TMA continues to operate in a highly hierarchical, top-down fashion (West, Yanda, \& Daly 2015). At the same time, the donors and international partners who initiated and supported the DCF and GFCS projects were both operating under the premise that SK was a key, missing input toward supporting the climate adaptation in rural Tanzania. This continued a legacy of technocratic development interventions aimed at 'modernizing' Maasai populations throughout the colonial and postcolonial eras in Tanzania (Galvin 2009; Hodgson 2001; Parkipuny 1979).

The task of developing 'usable' climate services in Tanzania was treated as a technical problem largely under the purview of climate scientists. Yet, some scientists at TMA, WMO, and other climate science producers involved in the projects, did not have a clear conceptualization of what co-production was, or what it should involve. For most climate scientists, the concepts of participation, user engagement, or coproduction remain unfamiliar. Indeed, at the beginning the GFCS project, a top scientist from TMA expressed their confusion to an international partner, asking: "what is co-production?" Nonetheless, TMA was designated as the central player in facilitating normative co-production.

As a result, TMA had a great deal of authority and wide leverage to define the types of climate information products that would be produced under the projects, while at the same time feeling pressure to comply with the demands of the donors and project coordinators to 'co-produce.' From the outset, TMA focused primarily on improving the production and dissemination of the existing seasonal climate forecast, which is produced twice a year for the October-November-December (OND) and March-April-May (MAM) rainy seasons. TMA's main accomplishment was the production of a downscaled (i.e. district-level) seasonal climate forecast, along with the establishment of a new modes of delivering the forecasts - e.g. text-message delivery through the FarmRadio platform. In this sense, TMA's contributions were largely an expansion of their ongoing activities. Further, TMA's services and interactions with district residents were largely interchangeable across the DCF and GFCS projects, despite the different approaches, constellations of stakeholders, and potential users involved. In fact, in Longido district, where both projects were operating 
concurrently, district officials and local residents had difficulty differentiating between the services provided by TMA under the DCF and GFCS projects based on planned discussion groups conducted in August 2016. This resulted in normative co-production approaches that focused on 'working around the edges' to improve the salience of the climate services, rather than opening up more controversial aspects of 'usable' knowledge - i.e. credibility and legitimacy - for debate.

\subsection{Knowledge Systems Criteria and the Politics of 'Usable' Knowledge}

As discussed in Section 1.1, the concept of 'usable' knowledge is generally employed in a normative fashion, focusing on how to enhance credibility, salience, and legitimacy. In contrast, we use an analytical co-production lens to examine the boundary work embedded within debates about 'usability' and the KSC - both within and across groups of actors and institutional scales. Results show how a narrow focus on one criterion (salience) came at the expense of other criteria (credibility, legitimacy), since these

would have more radically challenged existing social orders. In this section, we illustrate how normative co-production reinforced entrenched social orders and knowledge hierarchies, thereby failing to account for power relations and knowledge politics within the production of 'usable' knowledge.

\subsection{1 (Over-)emphasis on Salience}

Salience was addressed primarily through efforts to 'downscale' the seasonal forecasts to finer spatial resolutions. Pressure to provide downscaled forecasts arose in part from long-expressed desires from potential 'users' to receive more spatially specific information, but also from the need to concretely demonstrate to donors that climate services were responding to users' needs - i.e. the downscaled forecast was treated as 'evidence' of normative co-production between users and producers. In fact, the production of downscaled district-level forecasts was included as a formal indicator within the monitoring and evaluation (M\&E) framework for the GFCS project to demonstrate responsiveness to users' needs. Within the mid-term review of the GFCS project, climate scientists stressed the value of the downscaled forecast. A TMA official noted that downscaling the forecast was a "very big achievement" and that this "should be 
recognized," while WMO similarly acknowledged the downscaling as a "major success." At the same time, an international partner objected to downscaling as a way of enhancing overall usability, stating: "we can't agree to having user satisfaction based solely on the indicator of the downscaled forecast." Because of their roles in funding, convening, and sanctioning these projects, the power of external, international participants ended up strongly shaping what was considered salient, rather than the needs and views of local 'users.'

Scientists similarly hailed the downscaling of the seasonal climate forecast as an accomplishment within the DCF project. However, in this case, local participants did formally challenge the usability of these forecasts, although they were not given the chance to do so until the conclusion of the project, with no time left to reshape a more 'usable' product. During the final DCF project meeting in March 2015, a TMA scientist highlighted the newly available downscaled forecast as useful new tool. After his presentation, the TMA scientist attempted to return to his seat; however, the other meeting participants protested, demanding that he should return to the front of the room to field questions. Extension officers in the district complained that the most important aspect of the rainy season is when it will start and when it will end. Yet, the downscaled forecast only provided a prediction of the total amount of rainfall over the entire season, albeit at a finer spatial scale. Several other participants criticized the slow delivery of the forecasts, and one district official complained that "all we have is the statement" lacking sufficient detail to inform decisions. It was clear that the downscaled forecast did not meet 'users' expectations or requirements of usability.

Downscaling clearly had the potential to contribute (at least in part) to the enhanced salience of the forecasts. However, because of the narrow way in which 'successful' co-production was defined and measured within the projects, this resulted in a constrained focus on downscaling that ultimately limited the usability of the climate services provided.

\subsubsection{Obscuring Debates About Credibility: Solidifying Boundaries}

Within the GFCS and DCF projects in Tanzania, there were varying means of establishing and assessing credibility among actors involved in the projects. Among scientists at TMA, adhering to scientific protocols 
was paramount to assessing the credibility of information: "As a scientist, you need to analyze the information. You need to see what criteria they used to achieve credibility. You need to look at the source" (Climate Expert, \#5). For their seasonal forecasts, TMA used a simple measurement called a 'hit rate,' in which observed rainfall was compared with the forecast category with the highest probability to determine whether or not the forecast was credible.

While IK was broadly considered more credible than scientific knowledge at the village scale, among national and international actors it was necessary to subject IK to scientific standards before it could be included within standard forecasting procedures. An international stakeholder involved in the GFCS project noted that, while scientific and indigenous forecasts often "aligned," they were still not considered credible because "what is missing is scientific validation" (Climate Expert \#1). Another international stakeholder noted that it was possible to rely on IK, but that there was a need to "understand scientifically how this works" (Climate Expert \#4). In yet another instance, an international climate expert involved in the GFCS stated that with regard to IK, it would be necessary to "find the indigenous indicators that are backed by science and promote these" (Climate Expert \#7). In general, questions were raised during project meetings and events about the possibility of IK meeting sufficient "standards of integrity" (Climate Expert \#1).

Thus, despite claims about inclusion, in practice IK was only included in a way that would not threaten the dominance of scientific approaches to understanding climate. As stated by one Tanzanian scientist, "for us, indigenous people use different ways of predicting. Ours is much more scientific. Using theirs with ours would be contradicting ourselves. So, we keep the different forecasts separate and then we compare them. We do not mix the two..." (Climate Expert \#3). Because these forecasts were seen as the "required" climate service product by powerful actors (see Section 4.2.1), and TMA held more power in the process overall, they were able to impose standards of credibility, deciding how and when to acknowledge IK.

In contrast, stakeholders at the village scale had very different ways of assessing the credibility of information. Village-scale respondents were reluctant to definitively state whether any one piece of information was credible, as scientists did through the calculation of a single metric. Rather, residents strongly preferred to empirically verify the outcome of the forecast through personal observation and in 
terms related to livelihood activities and household well-being. As noted by several interviewees, there is a strong cultural norm among Maasai of confirming the sufficiency water and pasture in a particular location by sending a trusted family member as a scout before moving their cattle. Additionally, nearly all villagescale respondents stressed the importance of discussing information with the person delivering it to judge its credibility - whether the information was coming from their mother, their neighbor, or a climate scientist from Europe! Thus, credibility was always in relation to the type of information, the situation in which it was delivered, and the relationship with the actor providing the information.

While observational and interview data indicated that many district residents perceived IK to be highly credible, when such issues were discussed in a group setting within PDGs, boundaries between what is considered 'valid' knowledge shifted in response to the constellation of actors present. For example, one elder male participant in a PDG conducted in the village of Arkaria suggested that observed changes in the climate were attributable to the fact that people were no longer following customary practices due to increased prevalence of Christianity in Maasai areas: "the thing that has made people to change and stop doing sacrifices and worship of the trees is the church... There are a lot of churches that are confusing people." This suggestion elicited nervous laughter from the group and a reprobation from one participant, who expressed concern that the researchers (i.e. the lead author and research assistant) would "write and go tell that the people of Arkaria said there is no rainfall nowadays because of the churches" and that this wouldn't "make sense" (Swahili: haileti maana, literally "does not bring meaning") - which is to say, they would be made to look foolish for espousing customary beliefs rather than 'modern' or 'scientific' views. Thus, even among village residents, there were efforts to cordon off some knowledge as credible based on who this knowledge was being presented to and in what setting, further illustrating power differentials.

Importantly, both scientists and local residents pointed to the occurrence of climate change itself as a reason for discounting the credibility of knowledge. A primary justification for both projects was the notion that IK wasn't as reliable as it had been in the past, due to rapid changes in climate. At the same time, local residents made similar claims about scientific knowledge. A male respondent in Longido district (Int. \#11) stated that "I am hearing about [the scientific forecast] on the radio, but I am not using it because the weather 
has changed. Therefore, I can't follow the rain seasons of the radio."

Yet, within co-production processes, little effort was made to understand other ways of assessing credibility beyond scientific modes of inquiry. Moreover, even the scientific assessment of credibility was

given short shrift, with problems of the credibility of the scientific forecasts provided by TMA frequently downplayed. Underlying problems, such as sparse or insufficient observational data, were not seen as undermining the basic premise of the utility of scientific forecasts. Rather, efforts to improve credibility focused on building capacities to run more sophisticated climate models (e.g. numerical models). In the meantime, however, there was very little transparency with regard to the limitations of the scientific information - i.e., difficulties of downscaling, fundamental limits of seasonal prediction. This was bolstered by a persistent technological optimism that ensured continued investments in scientific observation networks and modeling capacities. In this way, the credibility of the forecasts was treated as a settled fact, one that did not have to be opened up for further investigation.

\subsubsection{Silencing Struggles Over Legitimacy}

Perceptions of legitimacy reflected both the processes of governing the development of climate services, as well as whose knowledge was included within their development. Struggles over the legitimacy of climate services governance in Tanzania were evident from an early stage in both the GFCS and DCF projects. TANDREC, a national level disaster management committee made of political appointees, was designated as the Steering Committee to facilitate engagement between 'producers' and 'users.' But, at the National Consultation Meeting, concerns were raised about the appropriateness of TANDREC as the governance platform for climate services, including its limited membership, timeliness of meeting schedules, and breadth of participant groups. As stated by one participant, "the Steering Committee should include people that are not present here at this meeting. There are a lot of institutions that work in climate change issues" (Climate Information Consultant, National Consultation Meeting, see also Daly, West, \& Yanda 2015). Debates ensued about how to develop institutional arrangements that could successfully support "dialogue between the users and producers of climate services" that could be "sustained beyond 
the consultation meeting workshop" (WMO Official, National Consultation Meeting).

Despite these objections, discussion of alternative or more inclusive governance arrangements for climate services development were soon shut down by a TMA official: "We should go with the recommendations as they are already institutionalized" - meaning that TANDREC should be instituted as the Steering Committee. It was apparent that the decision to embrace TANDREC as the Steering Committee had been pre-determined by WMO and TMA prior to the consultation meeting. There was little room for negotiating climate services governance at the national level.

Once again, the power wielded by international and national actors had an outsized influence on shaping the usability of whatever science might have been co-produced, at the expense of the intended local users and other participants. Concerns about the legitimacy of TANDREC as a platform for enabling engagement between producers and user of climate services as part of a process of co-production were borne out: TANDREC met in 2014 to endorse its role as Steering Committee for climate services, but met again only once more over the course of the three-year implementation of the GFCS project. This meant that TANDREC provided little substantive or operational guidance of climate services, while also failing to provide an effective space for interactions between 'producers' and 'users' of climate services.

Similar clashes over the legitimacy of normative co-production processes played out at sub-national scales within both the GFCS and DCF projects. In an effort to enhance the legitimacy of both processes and products, the DCF project established 'traditional' forecasting groups in several pilot districts (as discussed in Section 4.1). Members of the group reported being summoned by district officials to attend a seminar run by TMA. These indigenous experts described how they were "taught about climate change" (Planned Discussion Group, Longido District) and asked to describe their methods for predicting climate so that TMA could formally document these. Following the seminar, attendees reported being "told to send information" - i.e. indigenous forecasts — "every three months" (Planned Discussion Group, Longido District). The intention was that IK would be integrated into TMA's seasonal climate forecast to produce a 'hybrid' knowledge product.

However, the forecast group members were unsure about how the process of integrating knowledge 
would occur, and there was no evidence that the forecasts sent by the indigenous forecasting group were ever acknowledged or used by TMA. Most group members in Longido noted that they had not even received another seasonal forecast from TMA since the seminar, with several members stating during planned discussion groups that they saw the experiences as "a loss" — "we have given the information, but [TMA] haven't returned any information." One elder member of the Longido forecasting group noted: "you can't trust someone who comes once and says they want to work together, but then they never return."

The legitimacy of climate services development in Tanzania also reflected broader legacies of technocratic interventions, particularly among pastoralists and agro-pastoralists, such as the Maasai. These populations have experienced decades of economic development schemes intended to integrate pastoral livelihoods into 'modern', sedentary agricultural production systems. Expectations about new products, such as climate forecasts, are colored by these past experiences. Within planned discussion groups, villagescale respondents in Arkaria and Kiserian repeatedly stated that scientific climate forecasts provided by TMA were "for farmers" and "people in the cities" - i.e. not for them. Even those tasked with translation of forecasts to outlying villages do not always see them as the audience - an extension officer in Longido district, who participated in GFCS project trainings and also helped to facilitate traditional knowledge forecasting groups under the DCF project, noted that she didn't distribute the TMA forecasts because they were for "us experts" (Swahili: sisi wataalmu).

Long-time views of social status within Tanzanian society shaped attitudes and assumptions about each group involved in these projects, further jeopardizing efforts at legitimacy. Local participants felt that the climate scientists and other governmental agencies saw semi-nomadic pastoral livelihoods, customs, and culture as 'backward' and had little interest in listening to them or providing information that was compatible with their ways of life. A female planned group discussion participant from Longido district noted that "[national level actors] don't think it's important to use the ideas of people who haven't gone to school." Similarly, a male respondent from Monduli district pointed out that “the government doesn't really believe traditional knowledge concerning the weather." Such perceptions are reinforced by negative attitudes about pastoralist livelihoods more generally in Tanzania. Thus, while donors backing the projects 
assumed that involvement of national and sub-national actors would enhance the legitimacy of activities, there were often cultural and political tensions between national actors - who were relatively wealthy, educated, and thus had more access to power and control of co-production processes — and village residents in the pilot districts. Attempts to increase legitimacy within normative co-production processes thus reproduced differences in status.

\section{Discussion}

While most applications of the KSC seek to identify specific attributes of knowledge processes or products to be adjusted, we examine how power is embedded and enacted within the contested spaces and debates about the credibility, salience, and legitimacy of climate services. What can be gleaned from using the $\mathrm{KSC}$ as a lens for examining the ways in which power is exercised within the context of normative coproduction processes?

First of all, efforts to co-produce 'usable' knowledge involve deliberate choices with regard to how KSC are approached and constructed — and these decisions are not neutral. Normative co-production was intended to enhance the inclusion of multiple ways of knowing about climate in Tanzania. However, donors, international agencies, as well as stakeholders not directly connected to the use and production of information, influenced and shaped the way that normative co-production was carried out, starting with the conferring of unequal power and status on national political actors (such as TANDREC) and the national meteorological agency (TMA) within the process.

Given the resources that have been channeled toward the premise of 'co-produced' climate services by donors and international NGOs, TMA was under pressure to show that they were responsive to 'user' needs. Focusing on salience, through 'tailoring' the forecasts (i.e. through downscaling) demonstrated earnest and well-intentioned efforts by scientists to respond to the information needs of 'users.' However, these forecasts were not salient to the intended users. The dominance of scientific perspectives, entrenched methods of scientific production, and limited interaction, prevented a more meaningful exploration of how salience could have been improved. Indeed, a constrained focus on salience was the least threatening to the 
authority of scientific knowledge and obscured fundamental problems with credibility and legitimacy.

It has elsewhere been recognized that credibility is a relational concept, reflecting existing social relationships and histories (Wynne 1992). However, there was little effort to negotiate between difference in how credibility was assessed among agro-pastoralists in northern Tanzania and international and Tanzanian scientists - and even less recognition of the power differentials between the 'end-users' (e.g. socio-economically marginalized agro-pastoralists) and 'producers' (e.g. well-educated, relatively affluent scientists). Similarly, overcoming relations of distrust requires ongoing interactions over a long duration, as well as efforts to reassure potential 'users' that the information provided is not just the "continuation of policy by other means" (Clausewitz 1982, p. 119, as cited in Mitchell et al. 2006). This is particularly relevant for establishing the legitimacy of both the processes and the products of normative co-production among the Maasai in northern Tanzania, who have experienced a continual stream of technically oriented conservation and 'development' schemes during both the colonial and post-independence eras - often with negative results (Hodgson 2001).

Fully addressing issues around the credibility and legitimacy of the climate services provided would have required dealing directly with much 'messier' knowledge politics and power relations. Emphasis on normative co-production in these projects made TMA accountable in new ways - directly to Tanzanian citizens, who were the intended beneficiaries of the projects, as well as to international organizations (e.g. IIED, WMO) and the donors who had sponsored them (e.g. DfID, Norwegian Ministry of Foreign Affairs). These groups of stakeholders had very different demands, posing new challenges to the epistemic authority of TMA. Rather than emphasizing technical aspects of climate services, such as down-scaling forecasts, opening up questions of credibility and legitimacy would involve approaching the 'problem' of climate adaptation in fundamentally different ways (Goldman et al. 2018). The downscaled climate forecasts provided 'evidence' of successful co-production of knowledge between 'producers' and 'users' without rocking the proverbial boat — thereby leaving existing power structures unchallenged and unchanged.

As science is called upon to address policy-relevant questions, there can be challenges to maintaining the constructed boundaries between science and social/political domains (Jasanoff 1995). Efforts to 
facilitate normative co-production can make the constructed boundaries between science and society even more porous in order to allow increased communication and interaction. However, when science is asked to speak to specific issues and problems, it can open science up to additional scrutiny (Sarewitz \& Pielke 2007), which has important consequences. This new and imposed focus on co-production put TMA staff in a difficult and vulnerable position: they were now accountable on multiple fronts and on different terms than in the past, but with essentially the same human resources with which to respond to rapidly proliferating demands. TMA was under pressure to uphold the standing of scientific climate knowledge in the face of new modes of direct accountability to various stakeholders — both through the appearance of more inclusive processes, as well as by addressing perceived deficiencies in the scientific knowledge.

Processes of normative co-production, by their very nature, should open up possibilities for inclusion of alternative sources of knowledge. However, in this case, this also challenged the position of TMA as the sole and authoritative 'voice' of climate in Tanzania. Thus, the project meetings themselves were instances where the credibility and legitimacy - and associated epistemic authority - of TMA could be questioned relative to IK. Rather than open up deliberative spaces, the result was a narrow focus on the salience of the knowledge, with little regard to other aspects of usability. This shaped how scientific knowledge was presented, framed, and discussed, as well as how normative co-production of 'usable' knowledge was approached and implemented - and, more fundamentally, how relations of power between stakeholders were ultimately negotiated through the epistemic debates that ensued.

\section{Conclusion}

While often portrayed in depoliticized terms, normative co-production does not take place on a blank slate (Muñoz-Erickson 2014; Lövbrand 2011). Normative co-production processes within climate services are overlaid upon particular histories, existing institutions, and established relations between participants. Many participants have vested interests in maintaining established institutions, identities, and social orders,

which can either be advanced or threatened through normative co-production as their epistemic authority are challenged in new ways. As Watson-Verran and Turnbull $(1995$, p. 132) conclude, when multiple 
knowledges are involved, what is at stake is more than just participation; rather it is a "practical politics" that enables contestation, disagreement, and criticism of past relations.

It is clear that tokenistic consultation processes that deny some participants' status as holders of knowledge in their own right will not be sufficient. Moving beyond superficial engagement could involve taking seriously the different ways in which credibility of knowledge is achieved in different contexts and to be willing to put these in conversation with scientific modes of establishing validity of knowledge. Odora Hoppers (2011, p. 395) has called for developing shared understandings of credibility and legitimacy whereby scientists must also "transform their knowledge legitimation and accreditation cultures in order to build the linkages" among multiple knowledges, rather than demanding that all knowledge must conform to Western scientific standards as a baseline.

Taking this suggestion seriously would have radical consequences for how normative co-production might be approached in the future. In contrast to how co-production is currently being deployed in the field of climate services, this would put the onus on all participants to examine their own practices and perceptions to enable more productive engagement with other knowledges. This is not something that could be expected to happen quickly and would require openness on the part of all participants - most of all scientists. But it does indicate that there is a possibility to undertake normative co-production in positive and transformative ways. 